\title{
Vitamin A Is Systemically Bioavailable After Intratracheal Administration With Surfactant in an Animal Model of Newborn Respiratory Distress
}

\author{
AVASH J. SINGH, VADIM BRONSHTEIN, MINESH KHASHU, KYLE LEE, JAMES E. POTTS, \\ JAMES FRIEL, AND PHILIPPE CHESSEX
}

\begin{abstract}
Department of Pediatrics [A.J.S., V.B., M.K., K.L., J.E.P., P.C.], Children's and Women's Health Center of British Columbia, University of British Columbia, Vancouver, British Columbia, Canada V6H 3V4; Department of Human Nutritional Sciences [J.F.], University of
\end{abstract} Manitoba, Winnipeg, Manitoba, Canada R3T 2N2

\begin{abstract}
Chronic lung disease (CLD) is a major cause of long-term morbidity in extremely LBW infants with respiratory distress syndrome. Parenteral vitamin A administration decreases the risk of CLD. We tested the hypothesis that intratracheal vitamin A administration with surfactant is systemically bioavailable without interfering with the functional properties of exogenous surfactant. Newborn piglets were ventilated with $100 \% \mathrm{FiO}_{2}$ and sequential saline lavage induced respiratory distress syndrome. During lung injury induction, ventilator changes were allowed, but none were made following treatment allocation. Animals were assigned by chance in a blinded control trial to three groups: I = control; II = surfactant; III $=$ surfactant + vitamin A. Hemodynamics, lung mechanics, and blood gases were measured following instrumentation, pre- and posttreatment for $4 \mathrm{~h}$, at which time the liver was sampled for retinol determination. All parameters improved in animals receiving surfactant. A significant interaction existed between time and group for $\mathrm{PaO}_{2}$ and alveolar-arterial oxygen difference $\left(\mathrm{A}-\mathrm{aDO}_{2}\right)$. Hepatic levels of retinol were higher $(p<$ $0.001)$ in animals receiving retinyl acetate. Intratracheal administration of surfactant + vitamin A did not alter the beneficial effects of surfactant on lung compliance and gas exchange. Intratracheal Vitamin A was associated with rapid hepatic uptake. Further studies are warranted. (Pediatr Res 67: 619-623, 2010)
\end{abstract}

$\mathrm{C}$ hronic lung disease (CLD) of prematurity is the major cause of long-term disability of extremely LBW (ELBW) premature infants, and it is the most cost consumptive disease in Neonatal Intensive Care Unit graduates (1). CLD is characterized by poor lung growth, disruption of alveolarization, and impaired pulmonary vascular development (2). Histologic changes in the lungs of patients with CLD have been compared with the features observed in vitamin A deficient animal models (3). The consequences of vitamin A deficiency are reversible with restoration of normal vitamin A status $(4,5)$. This liposoluble vitamin is involved in the regulation and promotion of cellular differentiation and growth (6). Retinol, the active form of vitamin A, protects against hyperoxia-mediated cell-cycle ar-

Received October 13, 2009; accepted February 4, 2010.

Correspondence: Philippe Chessex, M.D., Division of Neonatology, Children's and Women's Health Centre, 4480 Oak Street, Vancouver, BC, Canada V6H 3V4; e-mail: pchessex@cw.bc.ca

Supported, in part, by a University-Industry grant from the Canadian Institutes of Health Research (Grant PP2-77273). rest, stimulates surfactant synthesis, and improves pulmonary vascularization promoting alveolar repair $(7,8)$. Premature infants are prone to vitamin A deficiency because they fail to accumulate retinol in the later half of pregnancy $(9,10)$. Moreover, premature infants start feeding late, their absorption of fat soluble vitamins is compromised, and the metabolic requirements for vitamin $\mathrm{A}$ are high (9).

Evidence from randomized clinical trials supports the use of parenteral vitamin A supplementation in premature infants at risk of CLD (11). On the other hand, oral supplementation of vitamin A does not alter the incidence of CLD in ELBW infants (12). Intramuscular administration of $5000 \mathrm{IU}$ vitamin A every second day for 4 wk reduced the incidence of CLD with a relative risk of $0.87-0.93$ and the number needed to treat and to benefit an infant is 12 (11). The treatment is considered painful and this may account for the report that vitamin A supplementation in ELBW infants is not routinely practiced (13).

Because majority of ELBW infants receive exogenous surfactant for respiratory distress syndrome (RDS), it was deemed relevant to investigate whether an admixture of vitamin A with surfactant as a lipophilic vehicle would be a less invasive route of vitamin A administration. Bronshtein et al. (14) found that retinyl acetate was miscible when mixed with bovine surfactant. However, the surface activity was $40 \%$ lower compared with surfactant alone, which raised questions about the functionality of this admixture in a clinical setting.

We hypothesized that intratracheal administration of retinol acetate mixed with surfactant would be bioavailable and would not adversely affect the pulmonary therapeutic properties of surfactant. The objective of this study was to determine the effect of intratracheal administration of a surfactant + retinyl acetate preparation on pulmonary mechanics, hemodynamics, gas exchange, and systemic bioavailability of vitamin $\mathrm{A}$ in a newborn piglet model of RDS. 


\section{METHODS}

Materials. Bovine lipid extract surfactant (BLES) was provided by BLES Biochemicals Inc, London, ON, Canada. Piglets were purchased through the University of British Columbia (UBC) Animal Care facility, retinyl acetate from Sigma Chemical Co.-Aldrich, Canada, and 100\% denatured alcohol from Sandoz, Boucherville, QC, Canada.

Experimental design. This blinded control animal trial was carried out in accordance with the Canadian Council of Animal Care guidelines and approved by the UBC Committee on Animal Care.

The newborn piglet is a well-established and widely used animal model for cardiorespiratory studies (15). To determine the effects of the administration of surfactant + vitamin A preparation on pulmonary mechanics and gas exchange, newborn piglets were anesthetized, mechanically ventilated, instrumented, and subjected to sequential saline lavages to induce hypoxemic respiratory failure $\left(\mathrm{PaO}_{2}<80 \mathrm{~mm} \mathrm{Hg}\right.$ in $\left.100 \% \mathrm{O}_{2}\right)$. The following outcome variables were measured: $\mathrm{PaO}_{2}, \mathrm{PaCO}_{2}, \mathrm{pH}, \mathrm{HCO}_{3}^{-}$, static lung compliance (Bear NVM-1 Neonatal Volume Monitor; Bear Medical System Inc. Riverside, CA), systemic arterial blood pressure, heart rate, and hepatic levels of vitamin $\mathrm{A}$; and alveolar-arterial oxygen difference $\left(\mathrm{A}-\mathrm{aDO}_{2}\right)$ was calculated and used as a marker of severity of lung injury. Measurements were performed and recorded: 1) following instrumentation, 2) following saline bronchoalveolar lavage to create hypoxemic respiratory failure associated with RDS, and 3) posttreatment every $30 \mathrm{~min}$ until $4 \mathrm{~h}$ after randomization. This study was undertaken as an acute physiologic experiment to determine bioavailability of vitamin A and to evaluate the efficacy of the surfactant + vitamin A admixture on pulmonary functions and facilitating gas exchange. At the end of the experiment ( $240 \mathrm{~min})$, the animals were euthanized by an i.v. overdose of pentobarbital $(50 \mathrm{mg} / \mathrm{kg})$. The liver was removed and immediately frozen in liquid nitrogen for retinol determination.

Animal preparation. Twelve mixed strain newborn piglets weighting $1.2-2.0 \mathrm{~kg}$ were obtained on their first or second day of life. The animals were placed in the supine position under a radiant heat lamp to maintain their body temperature as measured by a rectal probe and remained in the same position for the duration of the study.

Initial anesthetic induction was with inhaled halothane. An incision in the midline of the neck allowed the insertion of a catheter through the external jugular vein into the right atrium, through which maintenance i.v. D10W solution was infused. An arterial catheter was placed in the common carotid artery and connected to monitor blood pressure. A tracheotomy was performed and the piglet connected to a time-cycled pressure-limited neonatal ventilator (Sechrist, Anaheim, CA) using a continuous gas flow of $12 \mathrm{~L} / \mathrm{min}$ to provide assisted ventilation. Initial ventilator settings were 30 breaths per minute, $12-14 \mathrm{~cm} \mathrm{H}_{2} \mathrm{O}$ peak inspiratory pressure (PIP), $4 \mathrm{~cm} \mathrm{H}_{2} \mathrm{O}$ positive end-expiratory pressure (PEEP), and an inspiratory time $\left(T_{\mathrm{i}}\right)$ of $0.4 \mathrm{~s}$. On initiation of assisted ventilation, halothane was discontinued and intermittent bolus fentanyl was administered for sedation. Paralysis was achieved using pancuronium bromide.

Induction of lung injury. With the aim of inducing hypoxemic respiratory failure, lung injury was achieved by multiple lung lavages using a modification of the method described by Lachman (16). Lung lavage was performed with $35 \mathrm{~mL} / \mathrm{kg}$ of normal saline, warmed to $37^{\circ} \mathrm{C}$, administered through the endotracheal tube from a height of $60 \mathrm{~cm}$ above the piglet's head. Recovery of saline was accomplished by passive drainage by lowering the connecting tube $60 \mathrm{~cm}$ below the piglet's head. This drainage was augmented by gentle chest compressions. The average duration of each lavage procedure was $100 \mathrm{~s}$. Between the lung lavages ( 5 min apart), tidal volume $\left(V_{\mathrm{T}}\right)$ was maintained at baseline values by adjusting the PIP, which was increased to $18-20 \mathrm{~cm} \mathrm{H}_{2} \mathrm{O}$. The ventilator rate was adjusted during the lung injury to maintain $\mathrm{PaCO}_{2}<$ $60 \mathrm{~mm} \mathrm{Hg}$ and not to exceed an inspiratory:expiratory ratio of 1:1. Arterial blood gases were monitored every $2-4$ lavages. Lavages were continued until the $\mathrm{PaO}_{2}$ remained below $80 \mathrm{~mm} \mathrm{Hg}$ for $20 \mathrm{~min}$ in $100 \% \mathrm{O}_{2}$, keeping $V_{\mathrm{T}}$ and PEEP constant (17). At this point, the hypoxemic piglet was reconnected and intermittent positive pressure ventilation (IPPV) applied with no further ventilatory changes made during the remainder of the study period. Thirty minutes after the last lavage, animals were allocated by chance to the following three groups using random numbers.

Group I, control: IPPV with $100 \% \mathrm{O}_{2}(\mathrm{n}=4)$. Piglets were reconnected to the ventilator for the next $30 \mathrm{~min}$, the time at which the piglet was disconnected from the ventilator for $120 \mathrm{~s}$ to mimic the period of nonventilation of the surfactant administration procedure.

Group II, surfactant: IPPV with $100 \% \mathrm{O}_{2}+$ surfactant $(\mathrm{n}=4)$. Piglets were reconnected to the ventilator for the next $30 \mathrm{~min}$, the time at which a bolus dose of $5 \mathrm{~mL} / \mathrm{kg}$ of exogenous surfactant was administered via the side port connector of the endotracheal tube adaptor.

Group III, surfactant + vitamin A: IPPV with $100 \% \mathrm{O}_{2}+$ surfactant + retinyl acetate $(\mathbf{n}=4)$. Piglets were reconnected to the ventilator for the next
$30 \mathrm{~min}$, the time at which a bolus dose of $5 \mathrm{~mL} / \mathrm{kg}$ of exogenous surfactant mixed with retinyl acetate $25,000 \mathrm{IU} / \mathrm{kg}$ was administered via the side port connector of the endotracheal tube adaptor.

Following each of the study interventions, the animals were reconnected to the ventilator and ventilated for $240 \mathrm{~min}$, and during this period, no ventilator changes were allowed.

The study solutions were prepared off-site by a laboratory technician, individually for each animal, after allocation by chance to a group. The study solution was administered by the respiratory therapist. The study investigators were not present in the animal room at the time of the study intervention (control, surfactant, and surfactant + vitamin A). After the intervention, the study investigators ventilated the animal for $240 \mathrm{~min}$, without any further ventilator changes as per study protocol. The study investigators and laboratory staff performing the hepatic vitamin A analysis were unaware to which intervention group animals were allocated.

Surfactant + vitamin A preparation. On the day of the experiment, a solution of "surfactant + retinyl acetate + alcohol" was prepared as follows: a stock solution of 50,000 IU/mL retinyl acetate dissolved in alcohol $(100 \%$ denatured) was vortexed with $1 \mathrm{~mL}$ BLES. The preparation showed complete miscibility at room temperature and at $37^{\circ} \mathrm{C}$, macroscopically as well as microscopically $(100 \times)$ using light and fluorescence for precipitation over multiple samples (14).

Gas exchange. Arterial blood gases were collected starting at baseline (pre- and postsaline lung lavage) and every $30 \mathrm{~min}$ until the end of the experiment and analyzed (Radiometer, Copenhagen, Denmark).

Pulmonary mechanics, hemodynamics. Static lung compliance during ventilation was measured by a single breath expiratory occlusion technique (18) and normalized for animal weight. Analogue outputs of blood pressures, heart rate (Hewlett Packard monitor, \# 66S, Richmond BC, Canada), oxygen saturation (Pulse oximeter, Nellcor Puritan Bennett (Melville) Ltd, Canada), and ventilator settings were digitized, and data acquisition was done at baseline and then every $30 \mathrm{~min}$ for the duration of the study.

Vitamin A analysis. The liver was sampled $4 \mathrm{~h}$ after randomization and stored for retinol determination (19). The liver was homogenized and subjected to solvent extraction. To $200 \mathrm{mg}$ of each sample, $50 \mu \mathrm{L}$ of retinyl acetate (internal standard, $20 \mu \mathrm{g} / \mathrm{mL}$ ) and $2 \mathrm{~mL}$ of ethanol-water (1:1) mixture were added. The sample was vortex-mixed for a minute, and after the addition of $2 \mathrm{~mL}$ of hexane, the sample was vortex-mixed for an additional $1 \mathrm{~min}$. The sample was then centrifuged at $2400 \mathrm{rpm}$ for $10 \mathrm{~min}$, and the supernatant (hexane phase) containing vitamin A was removed, and the aqueous phase was subjected to a second extraction sequence. The hexane fractions were combined and dried under a stream of nitrogen gas at $30^{\circ} \mathrm{C}$. The dried sample was reconstituted with $500 \mu \mathrm{L}$ of methanol-chloroform (2:1), filtered on $0.45-\mu \mathrm{m}$ filter (Millipore C, Bedford, MA), and a portion of $50 \mu \mathrm{L}$ was injected into a HPLC system. Each sample was run in triplicate. Chromatography was performed using a Beckman Coulter Gold Chromatographic System (Mississauga, ON, Canada) consisting of a 126 solvent delivery module, a manual injector with a $50 \mu \mathrm{L}$ sample loop and UV/VIS 166 detector. Data were collected and analyzed with the Karat 32 software. A Synergi $4 \mu$ Hydro-RP $80 \AA(250 \times 4.6 \mathrm{~mm})$ from Phenomenex was used. Stock standard solutions of vitamin A (100 $\mu \mathrm{g} / \mathrm{L})$, vitamin E (100 $\mu \mathrm{g} / \mathrm{L})$, and retinyl acetate $(20 \mu \mathrm{g} / \mathrm{L})$ were prepared under subdued light in ethanol. A combination of five different concentrations from 1 to $10 \mu \mathrm{g} / \mathrm{mL}$ of these standards were prepared and used to obtain calibration curves. HPLC-grade methanol, hexane, and ethanol were from Fisher Scientific Company, Nepean, ON. The mobile phase consisted of $100 \% \mathrm{MeOH}$ filtered through a polytetrafluoroethylene (PTFE) $0.45-\mu \mathrm{m}$ filter (Millipore C, Bedford, MA) and degassed before each HPLC session.

Statistics. Univariate analyses were performed on all continuous variables and summary statistics expressed as the mean \pm SEM. A repeated measures analysis of variance was performed using a General Linear Model to determine whether the dependent variables differed by group, time, and whether there was a significant interaction (group $\times$ time). Post hoc comparisons were made using a Student Newman-Keuls procedure. Since multiple comparisons were made, the alpha was adjusted downward to $p<0.01$ to reduce the chance of making type I statistical error. All statistical analyses were completed using SAS Statistical Software, version 9.1.3 (SAS Institute, Cary, NC).

\section{RESULTS}

Following ventilation and before lung lavage, the 12 ventilated piglets (1-3 d of age, $1.02-2.27 \mathrm{~kg}$ ) exhibited similar blood gases and comparable parameters of lung function (Figs. 1, 2). On average, 13 sequential saline lung lavages were required to induce a clinical model of RDS the time at 

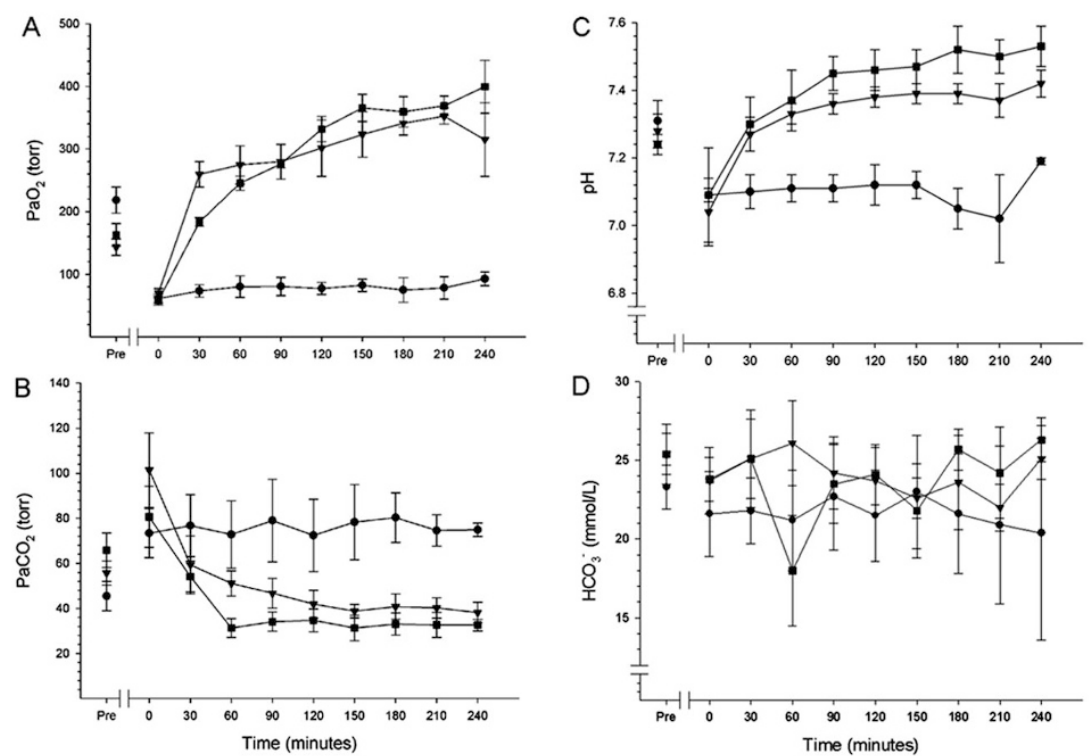

Figure 1. Effect of intratracheal administration of vitamin A with surfactant on respiratory gas exchanges. A) $\left.\left.\mathrm{PaO}_{2} ; B\right) \mathrm{PaCO}_{2} ; C\right) \mathrm{pH}$ and $D$ ) $\mathrm{HCO}_{3}{ }^{-}$. $\mathrm{After}$ establishment of the hypoxemic hypercarbic respiratory failure RDS model, animals were kept on constant ventilator settings. Exogenous surfactant was associated with a significant improvement over time in $\mathrm{PaO}_{2}, \mathrm{PaCO}_{2}$, and $\mathrm{pH}$ compared with the control group $\left(F_{26,81}=4.5\right.$ to 27.5, $\left.p<0.001\right)$. For $\mathrm{PaO}$, there was a significant interaction between surfactant $\boldsymbol{\nabla}$ and surfactant + vitamin A $\mathbf{\square}\left(F_{16,81}=5.5, p<0.001\right)$. Results are depicted as mean \pm the SEM (SEM), $n=4$ per group.
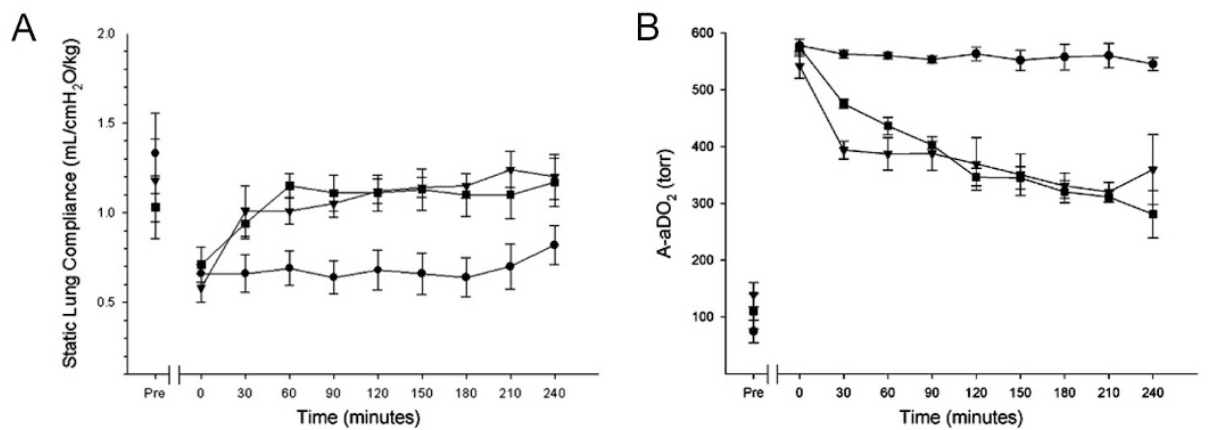

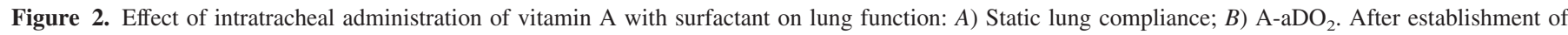
hypoxemic hypercarbic respiratory failure, animals were kept on constant ventilator settings. Exogenous surfactant was associated with a significant improvement over time in static lung compliance compared with the control group $\left(F_{26,81}=5.1,(p<0.001)\right.$. Exogenous surfactant was associated with a significant improvement over time in $\mathrm{A}-\mathrm{aDO}_{2}$ compared with the control group $-\left(F_{26,81}=9.6\right.$ to $\left.26.2, p<0.001\right)$. For $\mathrm{A}-\mathrm{aDO}_{2}$, there was a significant interaction between surfactant $\boldsymbol{\nabla}$ and surfactant + vitamin A $\boldsymbol{\square}\left(F_{16,81}=3.7\right.$ to 5.1, $\left.p<0.001\right)$. Results are depicted as mean \pm SEM, $n=4$ per group.

which the animals were in severe respiratory acidosis (Fig. $1 B$, $C$, and $D$ ) and hypoxemic respiratory failure (Fig. $1 A$ ) on assisted ventilation $\left(\mathrm{FiO}_{2} 1.0\right.$, PIP $20 \mathrm{~cm} \mathrm{H}_{2} \mathrm{O}$, PEEP $5 \mathrm{~cm}$ $\mathrm{H}_{2} \mathrm{O}$, rate 60 breaths/min). Static compliance decreased significantly after saline lavage (Fig. 2A). The figures show that the measured parameters were comparable in all three groups before randomization. The control piglets developed progressive acidosis and one died between 3.5 and $4.0 \mathrm{~h}$. All remaining animals survived for the duration of the study.

Gas exchange. The overall effects of treatment and time were significant $(p<0.0001)$ showing an improvement over time in arterial blood gases for the groups receiving surfactant (groups II and III) compared with group I. The intratracheal administration of surfactant was associated with a dramatic improvement in $\mathrm{PaO}_{2}, \mathrm{PaCO}_{2}$, and $\mathrm{pH}$ at 30 min. No changes were noted in $\mathrm{HCO}_{3}{ }^{-}$. The control group remained hypoxic, hypercarbic, and acidotic during the $4 \mathrm{~h}$ of the treatment phase of the study. There was a significant $(p<0.001)$ interaction between time and group for $\mathrm{PaO}_{2}$ and $\mathrm{A}-\mathrm{aDO}_{2}$ allowing for a separate analysis for each time point; the difference observed between surfactant with and without vitamin A at $240 \mathrm{~min}$ $(p<0.05)$ did not reach statistical significance.

Pulmonary compliance and hemodynamics. The overall effects of treatment and time were significant $(p<0.001)$ showing an improvement over time in lung function for the groups receiving surfactant (groups II and III) compared with group I. The intratracheal administration of surfactant was associated with a dramatic improvement in all measured parameters at $30 \mathrm{~min}$. The hemodynamic variables were comparable (heart rate and blood pressure) between all three groups in the pretreatment phase. Heart rate remained unchanged during the treatment phase, although blood pressure was significantly higher in the control group (data not shown).

Hepatic vitamin A. Hepatic levels of retinol measured $4 \mathrm{~h}$ after intratracheal administration were higher $(p<0.001)$ in animals in group III (Mean $\pm \mathrm{SD} ; 38 \pm 14 \mu \mathrm{g} / \mathrm{g}$ liver) 
compared with groups I (11 $\pm 4 \mu \mathrm{g} / \mathrm{g}$ liver $)$ and II $(13 \pm 6$ $\mu \mathrm{g} / \mathrm{g}$ liver), suggesting systemic bioavailability.

\section{DISCUSSION}

Our experimental model was successful in creating acute hypoxemic hypercarbic respiratory failure. Acidotic and hypoxemic animals responded positively to surfactant and surfactant + retinyl acetate with improved oxygenation, ventilation, and acidbase homeostasis (Fig. 1) and lung compliance (Fig. 2).

The administration of retinyl acetate with surfactant did not alter the efficacy of surfactant, despite its poor in vitro measured surface tension reducing properties (14). The potential advantage of intratracheal administration of vitamin A with surfactant would be to achieve a direct local effect with decreased systemic side effects. This could possibly occur through the effect that vitamin A has on stimulation of surfactant synthesis $(20,21)$. This is, however, unlikely because it happened independently from changes in lung compliance. Other potential explanations relate to the properties of vitamin A promoting alveolar repair $(22,4)$, protecting against hyperoxia-mediated cell-cycle arrest (23), or improving septation $(4,24,25)$. However, the duration of our experiment would be too short to enable lung repair. Another mechanism could be vitamin A modulated enhanced lung perfusion via stimulation of endogenous nitric oxide production (26), thereby improving ventilation/perfusion mismatch and augmenting oxygenation (27).

Hepatic levels were used to evaluate bioavailability because the liver is the biggest reservoir of retinol in the body. We were successful in using the large surface area of the lung in achieving systemic bioavailability of intratracheal vitamin A as observed by the rapid rise in hepatic retinol levels. We elected not to measure lung retinol content because we expected it to be potentially contaminated by intratracheal deposits of the surfactant + vitamin A admixture.

The intratracheal administration of drugs is widely used for the delivery of steroids and $\beta-2$ agonists in asthma and antibiotics in cystic fibrosis, and epinephrine, atropine, lidocaine, or naloxone. Inhaled forms of vitamin A have been successfully used in humans (28), with improved blood levels of vitamin A and retinol binding protein (29). Inhalation of pharmacological agents yields inconsistent delivery and poor distribution in the lung (30). Perfluorocarbons have been used successfully to deliver vasoactive agents and antibiotics directly to the lung $(31,32)$. However, perfluorocarbons are poor solvents for most bioactive molecules. Surfactant has been used to deliver Budesonide (pulmicort nebulizing suspension, Astra, Zeneca, Lund, Sweden) for local pulmonary effect $(33,34)$. Our study is the first report of using surfactant as a vehicle to deliver a biologically active agent such as vitamin A for systemic bioavailability.

Systemic administration of vitamin A has demonstrated only partial efficacy with regard to decreasing the incidence of CLD. Parenteral (i.v. and i.m.) delivery of vitamin A enhances plasma (35) and hepatic retinol content but not pulmonary content (36) despite the presence of retinoic acid receptors in the lungs (37). The novel aspect of this study relates to the local administration of vitamin A at the very onset of the RDS and its proven bioavailability. Bhatt et al. (38) reported that infants dying with CLD have abnormal alveolar microvessels and disordered expression of angiogenic growth factors. Vascular endothelial growth factor (VEGF) levels are lower in the lung, trachea, and plasma of neonates who died from acute RDS and CLD (39) supporting the hypothesis that lower lung VEGF expression impairs angiogenesis and alveolarization in babies with CLD. Others have linked vitamin A to VEGF upregulation $(40,41)$, which leads us to speculate that the acute beneficial effects of vitamin A as observed in our animal model could be through VEGF modulation via local and/or systemic mechanisms.

In newborn infants whose clinical condition requires surfactant replacement therapy, providing vitamin A with surfactant as a lipophilic vehicle may serve as a less-invasive mode of delivery than by using intramuscular injections. Our findings warrant further studies to test the biochemical, histologic, and clinical benefits of this noninvasive mode of co-administration of vitamin A in ELBW infants requiring surfactant.

Acknowledgments. We thank Dr. Dan Rurak for his assistance in setting up the animal model as well as to Jas Aulakh and Apollinaire Tsopmo for their technical help with the experiments.

\section{REFERENCES}

1. Walsh MC, Yao Q, Gettner P, Hale E, Collins M, Hensman A, Everette R, Peters N, Miller N, Muran G, Auten K, Newman N, Rowan G, Grisby C, Arnell K, Miller L, Ball B, McDavid G; National Institute of Child Health and Human Development Neonatal Research Network 2004 Impact of a physiologic definition on bronchopulmonary dysplasia rates. Pediatrics 114:1305-1311

2. Jobe AH 1999 The new BPD: an arrest of lung development. Pediatr Res 46:641643

3. Shenai JP 1999 Vitamin A supplementation in very low birth weight neonates: rationale and evidence. Pediatrics 104:1369-1374

4. Stahlman MT, Gray ME, Chytil F, Sundell H 1988 Effect of retinol on fetal lamb tracheal epithelium, with and without epidermal growtrh factor: a model for the effect of retinol on the healing lung of human premature infants. Lab Invest 59:25-35

5. Ozer EA, Kumral A, Ozer E, Duman N, Yilmaz O, Ozkal S, Ozkan H 2005 Effect of retinoic acid on oxygen induced lung injury in the newborn rat. Pediatr Pulmonol 39:35-40

6. Maden M, Hind M 2004 Retionoic acid in alveolar development, maintenance and regeneration. Philos Trans R Soc Lond B Biol Sci 359:799-808

7. Snyder JM, Jenkins-Moore M, Jackson SK, Goss KL, Dai HH, Bangsund PJ, Giguere V, McGowan SE 2005 Alveolarization in retinoic acid receptor-betadeficient mice. Pediatr Res 57:384-391

8. Hustead VA, Gutcher GR, Anderson SA, Zachman RD 1984 Relationship of vitamin A (retinol) status to lung disease in the preterm infant. J Pediatr 105:610-615

9. Shenai JP, Chytil F, Stahlman MT 1985 Vitamin A status of neonates with bronchopulmonary dysplasia. Pediatr Res 19:185-188

10. Greene HL, Phillips BL, Franck L, Fillmore CM, Said HM, Murrell JE, Moore ME, Briggs R 1987 Persistently low blood retinol levels during and after parenteral feeding of very low birth weight infants: examination of losses into intravenous administration sets and a method of prevention by addition to a lipid emulsion. Pediatrics 79:894-900

11. Darlow BA, Graham PJ 2002 Vitamin A supplementation for preventing morbidity and mortality in very low birthweight infants. Cochrane Database Syst Rev 2002;2:CD000501

12. Wardle SP, Hughes A, Chen S, Shaw NJ 2001 Randomized controlled trial of oral vitamin A supplementation in preterm infants to prevent chronic lung disease. Arch Dis Child Fetal Neonatal Ed 84:F9-F13

13. Ambalavanan N, Kennedy K, Tyson J, Carlo WA 2004 Survey of vitamin A supplementation for extremely-low-birth-weight infants: is clinical practice consistent with the evidence? J Pediatr 145:304-307

14. Bronshtein V, Venkatesh V, Aulakh J, Chessex P 2009 Surface activity of surfactant spike with vitamin A. Drug Des Devel Ther 2:145-150

15. Barrington KJ, Singh AJ, Etches PC, Finer NN 1999 Partial liquid ventilation with and without inhaled nitric oxide in a newborn piglet model of meconium aspiration. Am J Respir Crit Care Med 160:1922-1927

16. Lachmann B, Robertson B, Vogel J 1980 In vivo lung lavage as an experimental model of the respiratory distress syndrome. Acta Anaesthesiol Scand 24:231-236 
17. Sood SL, Balaraman V, Finn KC, Britton B, Uyehara CF, Easa D 1996 Exogenous surfactants in a piglet model of acute respiratory distress syndrome. Am J Respir Crit Care Med 153:820-828

18. Masters IB, Kondo C, Takahashi Y, Maloney JE, Wilkinson MW 1988 Single breath airway occlusion measurements of compliance and resistance utilizing a mechanical ventilator. Crit Care Med 16:620-623

19. Chessex P, Friel J, Harrison A, Rouleau T, Lavoie JC 2005 The mode of delivery of parenteral multivitamins influences nutrient handling in an animal model of total parenteral nutrition. Clin Nutr 24:281-287

20. Thébaud B, Barlier-Mur AM, Chailley-Heu B, Henrion-Caude A, Tibboel D, Dinh-Xuan AT, Bourbon JR 2001 Restoring effect of vitamin A on surfactant synthesis in nitrofen-induced congenital diaphragmatic hernia in rats. Am J Respir Crit Care Med 164:1083-1089

21. George TN, Snyder JM 1997 Regulation of surfactant protein gene expression by retinoic acid metabolites. Pediatr Res 41:692-701

22. Belloni PN, Garvin L, Mao CP, Bailey-Healy I, Leaffer D 2000 Effect of all-transretinoic acid in promoting alveolar repair. Chest 117:235S-241S

23. Nabeyrat E, Corroyer S, Besnard V, Cazals-Laville V, Bourbon J, Clement A 2001 Retinoic acid protects against hyperoxia mediated cell-cycle arrest of lung alveola epithelial cells by preserving late G1 cyclin activities. Am J Respir Cell Mol Biol 25:507-514

24. Massaro G, Massaro D 2000 Retinoic acid treatment partially rescues failed septation in rats and mice. Am J Physiol Lung Cell Mol Physiol 278:L955-L960

25. Massaro G, Massaro D 1996 Postnatal treatment with retinoic acid increases the number of pulmonary alveoli in rats. Am J Physiol 270:L305-L310

26. Seguin-Devaux C, Devaux Y, Latger-Cannard V, Grosjean S, Rochette-Egly C, Zannad F, Meistelman C, Mertes PM, Longrois D 2002 Enhancement of the inducible NO synthase activation by retinoic acid is mimicked by RARalpha agonist in vivo. Am J Physiol Endocrinol Metab 283:E525-E535

27. Moncada S 1997 Nitric oxide in the vasculature: physiology and pathophysiology. Ann N Y Acad Sci 811:60-67

28. Brooks AD, Tong W, Benedetti F, Kaneda Y, Miller V, Warrel RP 2000 Inhaled aerosolization of all-trans-retinoic acid for targeted pulmonary delivery. Cancer Chemother Pharmacol 46:313-318
29. Biesalski H, Reifen R, Fürst P, Edris M 1999 Retinyl palmitate supplementation by inhalation of an aerosol improves vitamin A status of preschool children in Gondar (Ethiopia). Br J Nutr 82:179-182

30. Lipworth BJ 1996 Pharmacokinetics of inhaled drugs. Br J Clin Pharmacol 42:697705

31. Wolfson MR, Greenspan JS, Shaffer TH 1996 Pulmonary administration of vasoactive substances by perfluorochemical ventilation. Pediatrics 97:449-455

32. Fox WW, Weis CM, Cox C, Farina C, Drott H, Wolfson MR, Shaffer TH 1997 Pulmonary administration of gentamicin during liquid ventilation in a newborn lamb lung injury model. Pediatrics 100:E5

33. Yeh TF, Lin HC, Chang CH, Wu TS, Su BH, Li TC, Pyati S, Tsai CH 2008 Early intratracheal instillation of Budenoside using surfactant as a vehicle to prevent chronic lung diseases in preterm infants: a pilot study. Pediatrics 121:e1310-e1318

34. Fajardo C, Levin D, Garcia M, Abrams D, Adamson I 1998 Surfactant versus saline as a vehicle for corticosteroid delivery to the lungs of ventilated rabbits. Pediatr Res 43:542-547

35. Shenai JP, Chytil F, Stahlman MT 1987 Clinical trial of vitamin A supplementation in infants susceptible to bronchopulmonary dysplasia. J Pediatr 111:269-277

36. Lavoie JC, Chessex P, Rouleau T, Tsopmo A, Friel J 2007 Shielding parenteral multivitamins from light increases vitamin $\mathrm{A}$ and $\mathrm{E}$ concentration in lung of newborn guinea pigs. Clin Nutr 26:341-347

37. McGowan SE, Harvey CS, Jackson SK 1995 Retinoids, retinoic acid receptors, and cytoplasmic retinoid binding proteins in perinatal rat lung fibroblasts. Am J Physiol 269:L463-L472

38. Bhatt AJ, Pryhuber GS, Huyck H, Watkins RH, Metlay LA, Maniscalco WM 2001 Disrupted pulmonary vasculature and decreased vascular endothelial growth factor, Flt-1, and TIE-2 in human infants dying with bronchopulmonary dysplasia. Am J Respir Crit Care Med 164:1971-1980

39. Lassus P, Turanlahti M, Heikkila P, Andersson LC, Nupponen I, Sarnesto A, Andersson S 2001 Pulmonary vascular endothelial growth factor and Flt-1 in fetuses, in acute and chronic lung disease, and in persistent pulmonary hypertension pf the newborn. Am J Respir Crit Care Med 164:1981-1987

40. Morrisey EE, Savani RC 2003 A potential bridge between glucocorticoid and retinoid effects on lung vascular development. Am J Respir Cell Mol Biol 28:5-8

41. Jankov RP, Tanswell AK 2004 Growth factors, postnatal lung growth and bronchopulmonary dysplasia. Paediatr Respir Rev 5 Suppl A:S265-S275 